\title{
Is an Endorectal Balloon Beneficial for Rectal Sparing After Spacer Implantation in Prostate Cancer Patients Treated With Hypofractionated Intensity-modulated Proton Beam Therapy? A Dosimetric and Radiobiological Comparison Study
}

Dalia Ahmad Khalil

Universitätsklinikum Essen: Universitatsklinikum Essen

Jörg Wulff

University Hospital Essen: Universitatsklinikum Essen

Danny Jazmati ( $\sim$ Danny.jazmati@uk-essen.de )

University Hospital Essen: Universitatsklinikum Essen

Dirk Geismar

University Hospital Essen: Universitatsklinikum Essen

Christian Bäumer

TU Dortmund: Technische Universitat Dortmund

Paul Heinz Kramer

universitätsklinikum essen

Theresa Steinmeier

Universitätsklinikum Essen: Universitatsklinikum Essen

Stefanie Schulze Schleithoff

Universitätsklinikum Essen: Universitatsklinikum Essen

Stephan Tschirdewahn

Universitätsklinikum Essen: Universitatsklinikum Essen

Boris Hadaschik

Universitätsklinikum Essen: Universitatsklinikum Essen

Beate Timmermann

Universitätsklinikum Essen: Universitatsklinikum Essen

Research

Keywords: Endorectal balloon, proton therapy, intensity-modulated therapy, prostate cancer, dose escalated radiation therapy, hypofractionated radiation therapy 
Posted Date: November 15th, 2021

DOI: https://doi.org/10.21203/rs.3.rs-1044144/v1

License: (c) (i) This work is licensed under a Creative Commons Attribution 4.0 International License. Read Full License 


\section{Abstract}

\section{Background}

The aim of this study is to examine the dosimetric influence of endorectal balloons (ERB) in rectal sparing in prostate cancer patients with implanted hydrogel rectum spacers treated with dose escalated/hypofractionated intensity modulated proton beam therapy (IMPT).

\section{Methods}

Ten patients with localised prostate cancer included in the ProRegPros study and treated at our centre were invastigated in this study. All patients underwent a placement of hydrogel rectum spacers before planning. Two planning CTs (with and without $120 \mathrm{~cm} 3$ fluid-filled ERB) were acquired for each patient. Dose prescription was set according to the used simultaneous integrated boost strategy with 72 Gray (Gy)/2.4 Gy/5 x weekly to prostate $1 \mathrm{~cm}$ of the seminal vesicle, and $60 \mathrm{~Gy} / 2 \mathrm{~Gy} / 5 \mathrm{x}$ weekly to prostate+2 $\mathrm{cm}$ of the seminal vesicle. Planning with two lateral-opposed IMPT beams was performed in both CTs. Rectal dosimetry values including dose-volume statistics and normal tissue complication probability (NTCP) in both plans were compared (non-ERB plans vs. ERB plans).

Results

For ERB plans compared to non-ERB, the reductions were $8.51 \pm 5.25$ Gy $(R B E)(p=0.000)$ and $15.76 \pm$ 11.11Gy $(P=0.001)$ for the mean and the median rectal dose, respectively. No significant reductions in rectal volumes receiving high dose levels were found. The use of ERB resulted in significant reduction in rectal volume receiving $50 \mathrm{~Gy}$ (RBE), $40 \mathrm{~Gy}$ (RBE), 30 Gy (RBE), 20 Gy (RBE), and 10 Gy (RBE) with $P$ values of $0.034,0.008,0.003,0.001$, and 0.001 , respectively. For the anterior rectum, no differences between ERB and non-ERB plans were observed. For the posterior rectum, ERB reduced rectal volumes received $30 \mathrm{~Gy}(\mathrm{RBE}), 20 \mathrm{~Gy}(\mathrm{RBE})$, and $10 \mathrm{~Gy}(\mathrm{RBE})$ with $\mathrm{P}$ values of $0.019,0.003$, and 0.001 , respectively. No significant reductions in mean or median rectal toxicity (Late rectal bleeding $\geq 2$, necrosis/stenosis, and Late rectal toxicity $\geq 3$ ) were observed when using the ERB according to NTCP models.

\section{Conclusion}

The ERB reduced rectal volumes exposed to intermediate/low dose levels. However, no significant reduction in rectal volumes receiving high/intermediate doses could be observed. No benefit but also no disadvantage of the ERB for late rectal toxicity was found according to available NTCP models.

\section{Introduction}

Despite advances in radiotherapy (RT) techniques, rectal morbidity related to prostate radiation treatment cannot be entirely avoided and carries implications for quality of life (QOL). Radiation dose escalation for prostate cancer patients using modern three-dimensional conformal radiotherapy (3D-CRT) and the more 
advanced Intensity modulated radiotherapy (IMRT) together with image guided radiotherapy (IGRT) has evolved over the past decade. Several randomised studies have demonstrated that dose escalation offers improved local control and biochemical control rates compared to conventional dose (1-6). However, escalating the total dose delivered to the prostate by 8-10 Gray (Gy) relative biological effectiveness (RBE) has been shown to significantly increase the risk of rectal toxicity by about $10 \%(2,7-9)$. Several trials relating rectum dose-volume characteristics to radiotherapy-induced rectal toxicities have been published (10-14). Based on these reports, the efforts of the radiation oncologists in the last decade have not only been directed to utilise modern radiotherapy techniques for patients with prostate cancer, but also to incorporate mechanical tools to increase the separation between prostate and rectum such as implantation of rectum-prostate spacers and/or using endorectal balloons (ERBs).

Significant reduction of intra-fractional prostate motion during radiotherapy by using ERB has been shown in a systematic review of 21 articles (15).The dosimetric effect of the ERB in reducing rectal radiation exposure during 3D-CRT, IMRT or stereotactic body radiation therapy for prostate cancer has been demonstrated by a number of studies (16-23). However, there are only few trials in the proton therapy field investigating the role of the ERB (24-28).

Because of higher sensitivity of the pencil beam scanning (PBS) technique to organ motion (29), ERB has mainly been used in our institution to stabilise the daily position and shape of the rectum and hence fixate the position of the prostate during treatment. Whether ERB retains benefit by decreasing the dose exposure to the rectum is unclear. Our goalwas to explore the dosimetric impact of the ERB on rectal dose and rectal normal tissue complication probability (NTCP) values in prostate cancer patients treated with dose escalated/hypofractionated IMPT who already have implanted rectum spacers.

\section{Methods}

Since August 2015, a prospective single-centre registry evaluating proton therapy for patients with localised prostate cancer (ProRegPros) has been carried out at the West German Proton Therapy Centre Essen (WPE). Two planning computed tomography (CT) scans before and after the insertion of the ERB were obtained for 10 consecutive patients undergoing prostate cancer treatment. All ten patients had been diagnosed with T1-T4, N0, M0 and PSA $\leq 50 \mathrm{ng} / \mathrm{ml}$. All patients were treated with dose escalated/moderate hypofractionated IMPT with $72 \mathrm{~Gy}(\mathrm{RBE})$ in 30 fractions. All patients selected for the analysis underwent hydrogel rectal spacer insertion and fiducial marker implantation one week before planning CT acquisition.

Written informed consent was obtained from all patients for their participation in the registry. The registry was approved by the ethical committee of the University of Duisburg Essen.CT-MRI Simulation

All patients drank $350 \mathrm{ml}$ water on an empty bladder 30 minutes prior to simulation. Patients were immobilised in supine position using a thermoplastic pelvic cast. The first planning CT was acquired for each patient in $1 \mathrm{~mm}$ slices. After that, the thermoplastic pelvic cast was removed and the ERB catheter 
was inserted in a knees-raised position and filled with $120 \mathrm{~cm}^{3}$ of fluid. Every patient was positioned and immobilized again using the laser alignment and immobilization mask markings, which had been placed during the first planning CT, and the second planning CT was acquired in $1 \mathrm{~mm}$ slices. T1/T2-weighted MRI were performed for all patients.

\section{Target volumes and OARs delineation:}

For each patient in every $\mathrm{CT}$, prostate, seminal vesicles, clinical target volumes (CTV) and organs at risk (OARs) were contoured after $\mathrm{CT} /$ magnetic resonance imaging (MRI) fusion for accurate prostate delineation. Two CTVs were defined; low risk CTV1 (prostate $+5 \mathrm{~mm}$ peri-prostatic tissue $+2 \mathrm{~cm}$ of the seminal vesicles), and high risk CTV2 (prostate $+1 \mathrm{~cm}$ of the seminal vesicles). The margins added to the CTV to create the corresponding planning target volumes (PTVs) were $5 \mathrm{~mm}$ in every direction except at the seminal vesicle region, where a $7 \mathrm{~mm}$ margin was applied (29). Dose prescription was $60 \mathrm{~Gy}$ (RBE) in 2 Gy to PTV1 and 72 Gy (RBE) in 2.4 Gy to PTV2 in 30 fractions as simultaneous integrated boost (SIB). The rectum was contoured as a solid organ extending from just above the anal verge up to the sigmoid flexure. Extra contours were generated for anterior and posterior rectum.

\section{SIB-IMPT Planning process:}

Dose calculation and optimisation for IMPT plans were performed with pencil beam algorithm using the RayStation treatment planning system version 6 (RaySearch Laboratories, Stockholm, Sweden). For all patients, fixed geometry plans were generated in both CTs using two lateral-opposed IMPT beams with the same optimisation goals. A margin of $3.5 \%$ proton beam range $+2 \mathrm{~mm}$ was included in the PTV in the beam direction to account for field-specific range uncertainty. For more consistency, all contours were generated by the same senior radiation oncologist and the same radiation physicist created all the treatment plans.

For all dose concepts, a generic relative biological effectiveness (RBE) factor of 1.1 (relative to that of Co60) was assumed.

\section{DVH analysis and rectal NTCP calculation:}

The dose-volume histogram (DVH) of the rectum was assessed and the following parameters were collected;

- For the whole rectum: $R V$ (rectal volume in $c c), D_{\text {max }}, D_{\text {mean }}, D_{\text {median }}$, and $R V x G y=$ percentage of rectal volume received X dose in Gy (RV72Gy, RV70Gy, RV65Gy, RV60Gy, RV55Gy, RV50Gy, RV40Gy, RV30Gy, RV20Gy, and RV10Gy).

- For the anterior rectum: $D_{\max }$ and Ant-RVxGy = percentage of anterior rectal volume received $x$ dose in Gy.

- For the posterior rectum: $D_{\text {max }}$ and Post-RVxGy = percentage of posterior rectal volume received $x$ dose in Gy. 
For the rectal NTCP calculation, the following biological models available in RayStation were employed;

- Layman Kutcher Burman (LKB) model for late rectal bleeding $\geq 2$ with $\mathrm{D} 50=81.8 \mathrm{~Gy}, y=3, \mathrm{~m}=0.22$, $\mathrm{n}=0.29$, and $\alpha / \beta=3(30)$.

- Poisson-LQ model for necrosis/stenosis with $D_{50}=80 \mathrm{~Gy}, y=2.2, \mathrm{~S}=1$, and $\alpha / \beta=3$ (27).

- LKB model for late effects grade $\geq 3$ with $D_{50}=80 \mathrm{~Gy}, \mathrm{~m}=0.15, \mathrm{n}=0.06$, and $\alpha / \beta=3.9$ (31).

We compared the rectal DVH parameters and the rectal NTCP values of the non-rectal balloon plans (nonERB group) with those of the rectal balloon plans (ERB group). The differences in DVH and NTCP indices were calculated ( $\Delta=$ mean value non-ERB plans - mean value ERB plans). Statistical analysis was performed using the IBM SPSS Statistics program V22. The Mann-Whitney-U-Test was used to compare means between the non-ERB plans and the ERB plans.

\section{Results}

\section{DVH Analysis:}

The $120 \mathrm{~cm}^{3}$ fluid-filled ERBs significantly increased the rectal volume in ERB plans compared to non-ERB plans. By analysis of the DVH of the whole rectum, we found that the ERB plans could reach lower values of $D_{\text {max }}, D 1, D_{\text {mean }}$, and $D_{\text {median }}$ in comparison to non-ERB plans. However, the differences in $D_{\max }$ and D1 were not statistically significant. There was a minimal non-statistically significant reduction in RV72Gy in favour of non-ERB plans compared to the ERB plans. Otherwise, the ERB plans could lower the rectal volumes exposed to different radiation doses compared to the non-ERB plans, with a non- significant reduction in RV70Gy, RV65Gy, RV60Gy, and RV55Gy and a significant reduction in RV50Gy, RV40Gy, RV30Gy, RV20Gy, and RV10Gy (Table 1, Figure 1).

Regarding analysis done for the anterior rectum, we found that the ERB could reduce the $D_{\text {max }}, D 1$, RV72Gy, RV70Gy, RV65Gy, RV60Gy, RV55G, RV50G, RV40G, RV30Gy, RV20Gy, and RV10Gy, but no statistically significant differences could be reached (Table 2).

For the posterior rectum, the $\mathrm{D}_{\max }$ and the $\mathrm{D} 1$ could be reduced in ERB plans in comparison to non-ERB plans, however without statistical significance. There were no statistically significant differences between the two groups regarding RV72Gy, RV70G, RV65Gy, RV60Gy, RV55Gy, or RV40Gy. Statistically significant differences were found between the two groups for rectal volumes receiving $30 \mathrm{~Gy}, 20 \mathrm{~Gy}$ and $10 \mathrm{~Gy}$ (Table 3).

\section{NTCP results:}

No statistically significant differences between the two study groups regarding the risk of NTCP for late rectal toxicities were determined. Comparisons of NTCP results for late rectal bleeding $\geq 2$, necrosis/stenosis, and late rectal toxicity $\geq 3$ are presented in Table 4 (mean comparison) and in figure 2 (median and full range of variation comparison). 


\section{Discussion}

Few trials using proton therapy for prostate patients have been directed to investigate the effectiveness of the ERB in rectal sparing (24), in reduction of the interfraction prostate motion (26), and in removal of rectal gas (25). Our aim was to investigate if an insertion of $120 \mathrm{~cm}^{3}$ fluid-filled ERB could spare rectum and hence reduce rectal NTCPs in patients who had undergone prior placement of hydrogel rectal spacers and were treated with dose escalated/hypofractionated IMPT to the prostate and the seminal vesicle.

In this study, the ERB increased the rectal volume by $137.35 \pm 32.58 \mathrm{~cm}^{3}$. The reduction in mean radiation dose received by the whole rectum in ERB plans compared to non-ERB plans was $8.51 \pm 5.25 \mathrm{~Gy}$ (RBE) $(P=0.000)$, and in $D_{\text {median }}$ it was $15.76 \pm 11.11 \mathrm{~Gy}$ (RBE) $(P=0.001)$. With regard to the maximum dose delivered to the rectum, we reported a 0.64 Gy (RBE) difference in the $D_{\text {max }}$, a 0.11 Gy (RBE) difference in D1 of the rectum, and a 0.21 Gy difference in D1 of the anterior rectum in favor of ERB plans, but with no statistical significance. For the posterior rectum, we found that the ERB could reduce the $D_{\text {max }}$, but with no statistical significance. In addition, the $D 1$ could be reduced for ERB plans by $11.11 \pm 13.93 \mathrm{~Gy}(\mathrm{RBE})$ with a marginal statistical significance $(P=0.059)$. Our results are similar to those reported by Elsayed et al., who applied 3D-CRT with 59.4 Gy (RBE) + 10 Gy (RBE) high dose-rate (HDR) brachytherapy in 12 patients. The authors found that for the teletherapy applied to a PTV including prostate $+9 \mathrm{~mm}$ safety margins, the application of a $60 \mathrm{~cm}^{3}$ air-filled ERB could lead to a decrease in $D_{\text {max }}$ of the anterior rectal wall and the rectum as complete organ but with no statistical significance. However, and owing to the dose distribution obtained from the 3D-CRT, the authors could demonstrate a reduction in the $\mathrm{D}_{\max }$ of the posterior rectal wall of $18.6 \mathrm{~Gy}$ (RBE) (47.1 Gy for non-ERB vs. 28.5 Gy for ERB), which was found to be significant $(P=0.01)(32)$.

Regarding rectal volumes receiving different dose levels, we did not find any statistically significant differences of rectal volumes at high/intermediate dose levels. Furthermore, through a separate analysis of the anterior rectum, we found that the ERB plans could not lead to significant differences in any of the DVH parameters examined in comparison to non-ERB plans. In the case of intermediate/low dose levels, the difference in rectal volumes between non-ERB plans and ERB plans was found to be 4.58, 6.82, 9.57, 12.87, and $15.78 \%$ for RV50Gy (RBE), RV40Gy (RBE), RV30Gy (RBE), RV20Gy (RBE), and RV10Gy (RBE), respectively, which was found to be statistically significant. By further analysis of the posterior rectum, we reported that the ERB could reduce the Post-RV30Gy (RBE) by $8.89 \pm 9.92 \%(P=0.019)$, the PostRV20Gy by $15.76 \pm 12.94 \%(P=0.003)$ and the Post-RV10Gy by $25.66 \pm 14.21 \%(P=0.001)$.

Our results are concurrent with results reported by Hille et al., who applied 72 Gy with conventional fractionation using 3D-CRT. The authors found that after inclusion of the prostate, the entire and the proximal seminal vesicles as CTV, a $60 \mathrm{~cm}^{3}$ air-filled ERB could lead to a significant decrease of the rectal wall receiving $40 \mathrm{~Gy}$ and $50 \mathrm{~Gy}$, while no significant decrease of the rectal wall receiving $60 \mathrm{~Gy}$, $65 \mathrm{~Gy}$, or $70 \mathrm{~Gy}$, could be found (33) . 
Other trials applying 3D-CRT demonstrated that insertion of ERB could lower rectal volume exposed to high doses. Early in 2002, Wachter et al., using 3D-CRT with $66 \mathrm{~Gy}$ for prostate cancer, tested the role of a $40 \mathrm{~cm}^{3}$ air-filled ERB on the rectal dose. The authors found that for PTV prostate only plans, the proportion of the rectum volume receiving doses larger than $90 \%$ could be reduced from $24 \%$ without ERB to $20 \%$ with ERB. However, for PTV prostate+ seminal vesicle plans, it was increased from $41 \%$ without ERB to $48 \%$ with ERB, due to posterior displacement of the seminal vesicle resulting from the application of the ERB (34). Van Lin et al. conducted a planning study testing 40,80, and $100 \mathrm{~cm}^{3}$ air-filled ERB vs. non-ERB plans, using three-dimensional conformal radiation therapy (DCRT) and IMRT plans, delivered to two different PTVs, with and without seminal vesicle. They found that in case of 3D-CRT the application of an ERB resulted in statistically significant reduction of the mean rectal wall dose, both if the amount of rectal wall volume irradiated to a dose level of $70 \mathrm{~Gy}$ or more and if the amount of rectal wall volume irradiated to a dose level of $50 \mathrm{~Gy}$ or more. However, in case of the IMRT, the authors could not report any statistically significant reduction in the rectal wall dose parameters for any of the ERBs (16). In contrast to Van Lin et al., Patel et al. conducted a planning study to detect the benefit of $60 \mathrm{~cm}^{3}$ air-filled ERB on the rectal dosimetry. They generated radiotherapy plans for 5 patients delivering 76 Gy either with 3DCRT or IMRT to target volumes with and without inclusion of the seminal vesicle and proved that inflation of the ERB in all cases and even in the context of IMRT resulted in a significant decrease in the absolute volume of rectal wall receiving greater than 60,65 , or 70 Gy (23).

The only trial investigating the role of the ERB in rectal sparing for patients treated with proton therapy was published by Vargas et al., who analyzed 20 proton plans for 15 patients who received doses of 78$82 \mathrm{~Gy}$ and found that the ERB decreased the volume of the rectum radiated to doses from 10 to $65 \mathrm{~Gy}$ ( $\mathrm{p}$ $\leq 0.05$ ), while no benefit was observed for doses $\geq 70$ Gy (24). In their trial, no hydrogel prostate rectum spacers were used.

Based on NTCP calculations, we found that the probability of late rectal toxicity could not be reduced by the application of the ERB. The mean NTCP for late rectal bleeding $\geq$ grade 2 was $2.6 \pm 0.97 \%$ for nonERB plans vs. $3.1 \pm 1.1 \%$ for ERB plans $(P=0.15)$. For necrosis/stenosis it was $5.5 \pm 1.78 \%$ for non-ERB plans vs. $5.6 \pm 2.22 \%$ for ERB plans ( $P=0.72$ ); for late rectal toxicity $\geq 3$ it was $13.1 \pm 1.37 \%$ for non-ERB plans vs. $13.3 \pm 3.02 \%$ for ERB plans $(P=0.593)$. Our results are similar to those reported by Van Lin et al. who used the LKB model with Emami parameters $(n=0.12, \mathrm{~m}=0.15$, and D50 $=80 \mathrm{~Gy})$ for late rectal NTCP calculations. In their trial, no statistically significant reduction of the NTCP could be demonstrated for the combination of IMRT with ERBs (40,80, and $100 \mathrm{~cm}^{3}$ air-filled). However, in their analysis, the ERB could improve the results of the 3D-CRT plans, in which a statistically significant reduction in the rectal NTCP for $100 \mathrm{~cm}^{3}$ air-filled ERB plans compared to non-ERB plans ( $15 \%$ vs. $24 \%$, respectively, $\left.P<0.0001\right)$ was found (16).

It has been proven that the rectal volumes exposed to intermediate and high doses are associated with developing late rectal toxicities. Storey et al. reported a significant correlation between the percentage of the rectum irradiated to $70 \mathrm{~Gy}$ or greater and the likelihood of developing late rectal complications in patients treated to $78 \mathrm{~Gy}$ (35). Kupelian et al. tested a short-course IMRT (70 Gy with 2.5 Gy per fraction) 
and demonstrated that only the volume of rectum receiving the $70 \mathrm{~Gy}$ (with a cutoff of $15 \mathrm{cc}$ ) was a significant predictor of rectal bleeding (11). Huang et al. also observed a significant volume effect at rectal doses of $60,70,75.6$, and $78 \mathrm{~Gy}$ and that the risk of developing rectal complications increased exponentially as larger volumes were irradiated (36). Zapatero et al. reported that the rectal $D_{\text {mean }}$ and the percentage of rectum receiving $>60$ Gy are correlated with grade 2 or worse rectal bleeding (37). On the other hand, other investigators demonstrated the likelihood of rectal toxicity for rectal volumes receiving an intermediate dose. Tucker and colleagues found that the incidence of grade 2 or worse late rectal bleeding increases within 2 years if $\geq 80 \%$ of the rectal wall is exposed to doses $>32 \mathrm{~Gy}$ (38). Jackson et al. reported that rectal bleeding was significantly correlated with the volumes exposed to $46 \mathrm{~Gy}$ in prostate cancer patients who received 70.2 and 75.6 Gy (39).

\section{Conclusion}

Our study suggests that the ERB could reduce the rectal volumes exposed to intermediate/low dose levels in prostate cancer patients with implanted rectum spacers treated with hypofractionated/dose escalated IMPT. We could not find any benefit of ERB in reducing rectal volumes receiving high/intermediate dose levels, which in turn and based on previous trials, can explain the lack of benefit of the ERB in reducing the NTCP values for late rectal toxicity in those patients. We think that the application of ERB does not add much benefit in patients treated with IMPT due to high capabilities of this technique to conform the dose to the target, which in turn reduces volumes of rectum exposed to high-dose region. Furthermore, reduction of rectum volumes receiving high dose can be achieved by spacer implantation. However, the potential effect of ERB in reducing volumetric changes of rectum filling and variabilities in rectal positioning during treatment cannot be neglected, especially for patients undergoing proton therapy due to high sensitivity of PBS dose distribution to inter- and intrafractional motion. This issue is currently under investigation at our centre and will be reported soon. Therefore, we are currently continuing to use the endorectal balloon at our centre to reduce motion

\section{Declarations}

\section{Authors' contribution}

DAK, DJ and JW wrote parts of the manuscript. BT, DG, DAK, JW designed the study. BH, CB, DG contributed significantly to the discussion on the interpretation of the results. All authors read and approved the final manuscript.

\section{Competing interests}

The authors declare that they have no competing interests.

\section{Availability of data and materials}

All data and materials can be accessed via DAK, in compliance with data protection guidelines. 


\section{Consent for publication}

All authors gave consent for the publication

\section{Ethics approval and consent to participate}

The registry was approved by the local ethical commission.

Conflict of Interest: All authors declare that they have no conflict of interest.

\section{Funding}

No

\section{Acknowledgements}

Not applicable

\section{References}

1. Michalski JM, Moughan J, Purdy J, Bosch W, Bruner DW, Bahary JP, et al. Effect of Standard vs Dose-Escalated Radiation Therapy for Patients With Intermediate-Risk Prostate Cancer: The NRG Oncology RTOG 0126 Randomized Clinical Trial. JAMA Oncol. 2018;4(6):e180039.

2. Kuban DA, Tucker SL, Dong L, Starkschall G, Huang EH, Cheung MR, et al. Long-term results of the M. D. Anderson randomized dose-escalation trial for prostate cancer. Int J Radiat Oncol Biol Phys. 2008;70(1):67-74.

3. Zietman AL, Bae K, Slater JD, Shipley WU, Efstathiou JA, Coen JJ, et al. Randomized trial comparing conventional-dose with high-dose conformal radiation therapy in early-stage adenocarcinoma of the prostate: long-term results from proton radiation oncology group/american college of radiology 9509. J Clin Oncol. 2010;28(7):1106-11.

4. Heemsbergen WD, Al-Mamgani A, Slot A, Dielwart MF, Lebesque JV. Long-term results of the Dutch randomized prostate cancer trial: impact of dose-escalation on local, biochemical, clinical failure, and survival. Radiother Oncol. 2014;110(1):104-9.

5. Beckendorf V, Guerif S, Le Prise E, Cosset JM, Bougnoux A, Chauvet B, et al. 70 Gy versus 80 Gy in localized prostate cancer: 5-year results of GETUG 06 randomized trial. Int J Radiat Oncol Biol Phys. 2011;80(4):1056-63.

6. Dearnaley DP, Jovic G, Syndikus I, Khoo V, Cowan RA, Graham JD, et al. Escalated-dose versus control-dose conformal radiotherapy for prostate cancer: long-term results from the MRC RT01 randomised controlled trial. Lancet Oncol. 2014;15(4):464-73. 
7. Peeters ST, Heemsbergen WD, Koper PC, van Putten WL, Slot A, Dielwart MF, et al. Dose-response in radiotherapy for localized prostate cancer: results of the Dutch multicenter randomized phase III trial comparing 68 Gy of radiotherapy with 78 Gy. J Clin Oncol. 2006;24(13):1990-6.

8. Dearnaley DP, Sydes MR, Graham JD, Aird EG, Bottomley D, Cowan RA, et al. Escalated-dose versus standard-dose conformal radiotherapy in prostate cancer: first results from the MRC RT01 randomised controlled trial. Lancet Oncol. 2007;8(6):475-87.

9. Delobel JB, Gnep K, Ospina JD, Beckendorf V, Chira C, Zhu J, et al. Nomogram to predict rectal toxicity following prostate cancer radiotherapy. PLoS One. 2017;12(6):e0179845.

10. Vargas C, Martinez A, Kestin LL, Yan D, Grills I, Brabbins DS, et al. Dose-volume analysis of predictors for chronic rectal toxicity after treatment of prostate cancer with adaptive image-guided radiotherapy. Int J Radiat Oncol Biol Phys. 2005;62(5):1297-308.

11. Kupelian PA, Reddy CA, Carlson TP, Willoughby TR. Dose/volume relationship of late rectal bleeding after external beam radiotherapy for localized prostate cancer: absolute or relative rectal volume? Cancer J. 2002;8(1):62-6.

12. Marzi S, Arcangeli G, Saracino B, Petrongari MG, Bruzzaniti V, laccarino G, et al. Relationships between rectal wall dose-volume constraints and radiobiologic indices of toxicity for patients with prostate cancer. Int J Radiat Oncol Biol Phys. 2007;68(1):41-9.

13. Ishikawa $\mathrm{H}$, Tsuji $\mathrm{H}$, Kamada $\mathrm{T}$, Hirasawa N, Yanagi T, Mizoe JE, et al. Risk factors of late rectal bleeding after carbon ion therapy for prostate cancer. Int J Radiat Oncol Biol Phys. 2006;66(4):1084-91.

14. Wachter S, Gerstner N, Goldner G, Potzi R, Wambersie A, Potter R. Rectal sequelae after conformal radiotherapy of prostate cancer: dose-volume histograms as predictive factors. Radiother Oncol. 2001;59(1):65-70.

15. Afkhami Ardekani M, Ghaffari H, Navaser M, Zoljalali Moghaddam SH, Refahi S. Effectiveness of rectal displacement devices in managing prostate motion: a systematic review. Strahlenther Onkol. 2021;197(2):97-115.

16. van Lin EN, Hoffmann AL, van Kollenburg P, Leer JW, Visser AG. Rectal wall sparing effect of three different endorectal balloons in 3D conformal and IMRT prostate radiotherapy. Int J Radiat Oncol Biol Phys. 2005;63(2):565-76.

17. Wong AT, Schreiber D, Agarwal M, Polubarov A, Schwartz D. Impact of the use of an endorectal balloon on rectal dosimetry during stereotactic body radiation therapy for localized prostate cancer. Pract Radiat Oncol. 2016;6(4):262-7.

18. Teh BS, Lewis GD, Mai W, Pino R, Ishiyama H, Butler EB. Long-term outcome of a moderately hypofractionated, intensity-modulated radiotherapy approach using an endorectal balloon for patients 
with localized prostate cancer. Cancer Commun (Lond). 2018;38(1):11.

19. Wortel RC, Oomen-de Hoop E, Heemsbergen WD, Pos FJ, Incrocci L. Moderate hypofractionation in intermediate and high risk, localized prostate cancer: Health-related quality of life from the randomized, phase 3 HYPRO trial. Int J Radiat Oncol Biol Phys. 2018.

20. Deville C, Both S, Bui V, Hwang WT, Tan KS, Schaer M, et al. Acute gastrointestinal and genitourinary toxicity of image-guided intensity modulated radiation therapy for prostate cancer using a daily water-filled endorectal balloon. Radiat Oncol. 2012;7:76.

21. Vlachaki MT, Teslow TN, Ahmad S. Impact of endorectal balloon in the dosimetry of prostate and surrounding tissues in prostate cancer patients treated with IMRT. Med Dosim. 2007;32(4):281-6.

22. Smeenk RJ, van Lin EN, van Kollenburg P, Kunze-Busch M, Kaanders JH. Anal wall sparing effect of an endorectal balloon in 3D conformal and intensity-modulated prostate radiotherapy. Radiother Oncol. 2009;93(1):131-6.

23. Patel RR, Orton N, Tome WA, Chappell R, Ritter MA. Rectal dose sparing with a balloon catheter and ultrasound localization in conformal radiation therapy for prostate cancer. Radiother Oncol. 2003;67(3):285-94.

24. Vargas C, Mahajan C, Fryer A, Indelicato D, Henderson RH, McKenzie C, et al. Rectal dose-volume differences using proton radiotherapy and a rectal balloon or water alone for the treatment of prostate cancer. Int J Radiat Oncol Biol Phys. 2007;69(4):1110-6.

25. Wootton LS, Kudchadker RJ, Beddar AS, Lee AK. Effectiveness of a novel gas-release endorectal balloon in the removal of rectal gas for prostate proton radiation therapy. J Appl Clin Med Phys. 2012;13(5):3945.

26. Hedrick SG, Fagundes M, Robison B, Blakey M, Renegar J, Artz M, et al. A comparison between hydrogel spacer and endorectal balloon: An analysis of intrafraction prostate motion during proton therapy. J Appl Clin Med Phys. 2017;18(2):106-12.

27. Agren Cronqvist AK, Kallman P, Turesson I, Brahme A. Volume and heterogeneity dependence of the dose-response relationship for head and neck tumours. Acta Oncol. 1995;34(6):851-60.

28. Vanneste BGL, van Wijk Y, Lutgens LC, Van Limbergen EJ, van Lin EN, van de Beek K, et al. Dynamics of rectal balloon implant shrinkage in prostate VMAT : Influence on anorectal dose and late rectal complication risk. Strahlenther Onkol. 2018;194(1):31-40.

29. Qamhiyeh S, Geismar D, Pottgen C, Stuschke M, Farr J. The effects of motion on the dose distribution of proton radiotherapy for prostate cancer. J Appl Clin Med Phys. 2012;13(3):3639. 
30. Rancati T, Fiorino C, Gagliardi G, Cattaneo GM, Sanguineti G, Borca VC, et al. Fitting late rectal bleeding data using different NTCP models: results from an Italian multi-centric study (AIROPROS0101). Radiother Oncol. 2004;73(1):21-32.

31. Dale E, Hellebust TP, Skjonsberg A, Hogberg T, Olsen DR. Modeling normal tissue complication probability from repetitive computed tomography scans during fractionated high-dose-rate brachytherapy and external beam radiotherapy of the uterine cervix. Int J Radiat Oncol Biol Phys. 2000;47(4):963-71.

32. Elsayed H, Bolling T, Moustakis C, Muller SB, Schuller P, Ernst I, et al. Organ movements and dose exposures in teletherapy of prostate cancer using a rectal balloon. Strahlenther Onkol. 2007;183(11):61724.

33. Hille A, Schmidberger $\mathrm{H}$, Tows $\mathrm{N}$, Weiss $\mathrm{E}$, Vorwerk $\mathrm{H}$, Hess CF. The impact of varying volumes in rectal balloons on rectal dose sparing in conformal radiation therapy of prostate cancer. A prospective three-dimensional analysis. Strahlenther Onkol. 2005;181(11):709-16.

34. Wachter S, Gerstner N, Dorner D, Goldner G, Colotto A, Wambersie A, et al. The influence of a rectal balloon tube as internal immobilization device on variations of volumes and dose-volume histograms during treatment course of conformal radiotherapy for prostate cancer. Int J Radiat Oncol Biol Phys. 2002;52(1):91-100.

35. Storey MR, Pollack A, Zagars G, Smith L, Antolak J, Rosen I. Complications from radiotherapy dose escalation in prostate cancer: preliminary results of a randomized trial. Int J Radiat Oncol Biol Phys. 2000;48(3):635-42.

36. Huang EH, Pollack A, Levy L, Starkschall G, Dong L, Rosen I, et al. Late rectal toxicity: dosevolume effects of conformal radiotherapy for prostate cancer. Int J Radiat Oncol Biol Phys. 2002;54(5):1314-21.

37. Zapatero A, Garcia-Vicente F, Modolell I, Alcantara P, Floriano A, Cruz-Conde A, et al. Impact of mean rectal dose on late rectal bleeding after conformal radiotherapy for prostate cancer: dose-volume effect. Int J Radiat Oncol Biol Phys. 2004;59(5):1343-51.

38. Tucker SL, Dong L, Cheung R, Johnson J, Mohan R, Huang EH, et al. Comparison of rectal dosewall histogram versus dose-volume histogram for modeling the incidence of late rectal bleeding after radiotherapy. Int J Radiat Oncol Biol Phys. 2004;60(5):1589-601.

39. Jackson A, Skwarchuk MW, Zelefsky MJ, Cowen DM, Venkatraman ES, Levegrun S, et al. Late rectal bleeding after conformal radiotherapy of prostate cancer. II. Volume effects and dose-volume histograms. Int J Radiat Oncol Biol Phys. 2001;49(3):685-98.

\section{Tables}


Table 1: DVH analysis for the whole rectum comparing between the non-ERB plans and ERB plans: 


\begin{tabular}{|c|c|c|c|c|c|c|c|}
\hline & \multirow{2}{*}{$\begin{array}{l}\text { Study } \\
\text { group }\end{array}$} & \multirow[t]{2}{*}{ mean } & \multirow[t]{2}{*}{ SD } & \multirow[t]{2}{*}{ Range } & \multicolumn{2}{|c|}{$\operatorname{Diff}(\Delta)^{d}$} & \multirow[t]{2}{*}{$P$ value } \\
\hline & & & & & mean & SD & \\
\hline \multirow[t]{2}{*}{$\mathrm{RV}^{\mathrm{a}}$} & non-ERB & 90.79 & 42.34 & 42.08-183.51 & 137.35 & 32.58 & 0.000 \\
\hline & ERB & 228.14 & 31.65 & 179.79-267.54 & & & \\
\hline \multirow[t]{2}{*}{$D_{\max }{ }^{b}$} & non-ERB & 73.62 & 0.77 & $72.6-74.8$ & 0.64 & 0.85 & 0.103 \\
\hline & ERB & 72.98 & 0.55 & 72.6- 74.4 & & & \\
\hline \multirow{2}{*}{$D_{\text {mean }}{ }^{b}$} & non-ERB & 31.42 & 4.98 & $24.20-42.29$ & 8.51 & 5.25 & 0.000 \\
\hline & ERB & 22.91 & 3.0 & $18.79-27.53$ & & & \\
\hline \multirow{2}{*}{$D_{\text {median }}{ }^{b}$} & non-ERB & 26.34 & 9.66 & $13.06-45.25$ & 15.76 & 11.11 & 0.001 \\
\hline & ERB & 10.57 & 5.89 & $4.39-21.52$ & & & \\
\hline \multirow[t]{2}{*}{$\mathrm{D} 1^{\mathrm{b}}$} & non-ERB & 72.49 & 0.53 & 71.59-73.29 & 0.11 & 0.52 & 0.363 \\
\hline & ERB & 72.38 & 0.16 & 72.21-72.78 & & & \\
\hline \multirow[t]{2}{*}{ RV72Gy ${ }^{c}$} & non-ERB & 3.42 & 1.73 & $0.34-5.60$ & -0.38 & 2.24 & 0.734 \\
\hline & ERB & 3.80 & 1.07 & $1.96-5.30$ & & & \\
\hline \multirow[t]{2}{*}{ RV70Gy c } & non-ERB & 7.90 & 3.4 & $2.12-13.29$ & 0.58 & 4.42 & 0.597 \\
\hline & ERB & 7.32 & 2.03 & $3.89-9.84$ & & & \\
\hline \multirow[t]{2}{*}{ RV65Gy ${ }^{c}$} & non-ERB & 13.98 & 4.3 & $5.93-21.28$ & 1.66 & 5.45 & 0.257 \\
\hline & ERB & 12.31 & 2.54 & $7.66-15.98$ & & & \\
\hline \multirow[t]{2}{*}{ RV60Gy ${ }^{c}$} & non-ERB & 18.74 & 4.85 & $9.63-27.32$ & 1.10 & 6.99 & 0.345 \\
\hline & ERB & 17.64 & 5.62 & $11.17-31.51$ & & & \\
\hline \multirow[t]{2}{*}{ RV55Gy ${ }^{c}$} & non-ERB & 23.37 & 6.37 & $13.11-37.72$ & 4.02 & 8.15 & 0.082 \\
\hline & ERB & 19.35 & 3.15 & $14.85-23.96$ & & & \\
\hline \multirow[t]{2}{*}{ RV50Gy ${ }^{c}$} & non-ERB & 26.87 & 5.59 & $16.49-37.51$ & 4.58 & 7.37 & 0.034 \\
\hline & ERB & 22.29 & 3.43 & $17.52-27.51$ & & & \\
\hline \multirow[t]{2}{*}{ RV40Gy ${ }^{c}$} & non-ERB & 34.50 & 6.19 & $23.45-46.37$ & 6.82 & 8.02 & 0.008 \\
\hline & ERB & 27.68 & 3.74 & $22.36-33.83$ & & & \\
\hline \multirow[t]{2}{*}{ RV30Gy ${ }^{c}$} & non-ERB & 42.67 & 6.60 & $32.64-54.68$ & 9.57 & 8.23 & 0.003 \\
\hline & ERB & 33.10 & 4.4 & $27.05-40.37$ & & & \\
\hline RV20Gyc & non-ERB & 52.33 & 7.75 & $42.85-65.88$ & 12.87 & 8.75 & 0.001 \\
\hline
\end{tabular}




\begin{tabular}{|llllllll|} 
& ERB & 39.46 & 5.09 & $32.58-47.58$ & & & \\
\multirow{2}{*}{ RV10Gy ${ }^{c}$} & non-ERB & 64.57 & 8.55 & $54.38-81.85$ & 15.78 & 8.91 & 0.001 \\
& ERB & 48.77 & 6.13 & $40.99-57.68$ & & & \\
\hline
\end{tabular}

a Rectal volume in $\mathrm{cm}^{3} ;{ }^{\mathrm{b}}$ Dose in $\mathrm{Gy} ;{ }^{\mathrm{b}} \mathrm{RVXGy}=$ Percentage of rectal volume received $\mathrm{x}$ dose;

${ }^{\mathrm{d}} \Delta$ difference between the non-ERB plans and the ERB plans (mean value non-ERB plans - mean value ERB plans)

Table 2: DVH analysis for the anterior rectum comparing between the non-ERB plans and ERB plans: 


\begin{tabular}{|c|c|c|c|c|c|c|c|}
\hline & \multirow{2}{*}{$\begin{array}{l}\text { Study } \\
\text { group }\end{array}$} & \multirow[t]{2}{*}{ mean } & \multirow[t]{2}{*}{ SD } & \multirow[t]{2}{*}{ Range } & \multicolumn{2}{|c|}{$\operatorname{Diff}(\Delta)^{c}$} & \multirow[t]{2}{*}{$P$ value } \\
\hline & & & & & mean & SD & \\
\hline \multirow{2}{*}{ Ant- $D_{\max }{ }^{a}$} & non-ERB & 73.62 & 0.77 & $72.6-74.8$ & 0.64 & 0.85 & 0.103 \\
\hline & ERB & 72.98 & 0.545 & 72.6- 74.4 & & & \\
\hline \multirow[t]{2}{*}{ Ant-D1 ${ }^{a}$} & non-ERB & 72.77 & 0.72 & 71.31-73.73 & 0.21 & 0.69 & 0.326 \\
\hline & ERB & 72.56 & 0.23 & 72.30-73.01 & & & \\
\hline \multirow[t]{2}{*}{ Ant-RV72Gy ${ }^{b}$} & non-ERB & 5.99 & 3.17 & $0.66-12.32$ & -1.14 & 3.71 & 0.290 \\
\hline & ERB & 7.13 & 2.1 & $3.78-10.29$ & & & \\
\hline \multirow[t]{2}{*}{ Ant-RV70Gy ${ }^{b}$} & non-ERB & 14.44 & 5.36 & $4.98-21.80$ & -0.95 & 6.49 & 0.705 \\
\hline & ERB & 15.39 & 3.98 & $8.28-20.98$ & & & \\
\hline \multirow[t]{2}{*}{ Ant-RV65Gy b } & non-ERB & 22.84 & 5.75 & $11.39-31.05$ & -1.22 & 8.41 & 0.940 \\
\hline & ERB & 24.05 & 5.7 & $14.79-31.02$ & & & \\
\hline \multirow[t]{2}{*}{ Ant-RV60Gy b } & non-ERB & 31.74 & 7.51 & $18.49-41.66$ & 0.93 & 9.11 & 0.545 \\
\hline & ERB & 30.81 & 6.61 & $21.55-39.18$ & & & \\
\hline \multirow[t]{2}{*}{ Ant-RV55Gy b } & non-ERB & 38.66 & 8.32 & $25.13-48.53$ & 1.19 & 10.52 & 0.734 \\
\hline & ERB & 37.47 & 7.16 & $28.65-48.53$ & & & \\
\hline \multirow[t]{2}{*}{ Ant-RV50Gy ${ }^{b}$} & non-ERB & 47.34 & 7.41 & $31.36-56.39$ & 3.88 & 11.14 & 0.226 \\
\hline & ERB & 43.46 & 7.29 & $34.42-54.28$ & & & \\
\hline \multirow[t]{2}{*}{ Ant-RV40Gy b } & non-ERB & 59.11 & 7.64 & $42.45-68.87$ & 6.6 & 11.88 & 0.174 \\
\hline & ERB & 52.51 & 8.60 & $42.48-65.22$ & & & \\
\hline \multirow[t]{2}{*}{ Ant-RV30Gy b } & non-ERB & 69.25 & 7.9 & $52.49-78.39$ & 7.65 & 12.21 & 0.059 \\
\hline & ERB & 61.60 & 9.05 & $50.20-76.17$ & & & \\
\hline \multirow[t]{2}{*}{ Ant-RV20Gy b } & non-ERB & 78.84 & 9.65 & 61.83-89.52 & 8.31 & 12.81 & 0.059 \\
\hline & ERB & 70.53 & 9.03 & $58.28-84.13$ & & & \\
\hline \multirow[t]{2}{*}{ Ant-RV10Gy ${ }^{b}$} & non-ERB & 85.2 & 9.44 & $71.7-96.11$ & 4.17 & 11.75 & 0.174 \\
\hline & ERB & 81.03 & 7.9 & 68.21-91.01 & & & \\
\hline
\end{tabular}

${ }^{a}$ Dose in Gy; ${ }^{b} \mathrm{RVXGy}=$ Percentage of ant-rectal volume received $\mathrm{X}$ dose; ${ }^{\mathrm{c}} \Delta$ difference between the nonERB plans and the ERB plans (mean value non-ERB plans - mean value ERB plans)

Table 3: DVH analysis for the posterior rectum comparing between the non-ERB plans and ERB plans: 


\begin{tabular}{|c|c|c|c|c|c|c|c|}
\hline & \multirow{2}{*}{$\begin{array}{l}\text { Study } \\
\text { group }\end{array}$} & \multirow[t]{2}{*}{ mean } & \multirow[t]{2}{*}{ SD } & \multirow[t]{2}{*}{ Range } & \multicolumn{2}{|c|}{$\operatorname{Diff}(\Delta)^{c}$} & \multirow[t]{2}{*}{$P$ value } \\
\hline & & & & & mean & SD & \\
\hline \multirow[t]{2}{*}{$D_{\max }{ }^{a}$} & non-ERB & 60.24 & 9.16 & $47.60-72.60$ & 3.83 & 12.41 & 0.406 \\
\hline & ERB & 56.41 & 10.54 & $42.80-70.60$ & & & \\
\hline \multirow[t]{2}{*}{$\mathrm{D} 1^{\mathrm{a}}$} & non-ERB & 37.36 & 11.82 & $23.66-57.94$ & 11.11 & 13.93 & 0.059 \\
\hline & ERB & 72.56 & 0.23 & $72.3-73.01$ & & & \\
\hline \multirow[t]{2}{*}{ Post-RV72Gy b } & non-ERB & 0.11 & 0.35 & $0-1.14$ & 0.11 & 0.36 & 0.317 \\
\hline & ERB & 0 & 0 & 0 & & & \\
\hline \multirow[t]{2}{*}{ Post-RV70Gy b } & non-ERB & 0.51 & 1.6 & $0-5.06$ & 0.51 & 1.6 & 0.503 \\
\hline & ERB & 0 & 0 & $0-0.02$ & & & \\
\hline \multirow[t]{2}{*}{ Post-RV65Gy b } & non-ERB & 1.08 & 3.31 & $0-10.49$ & 1.06 & 3.29 & 0.829 \\
\hline & ERB & 0.03 & 0.07 & $0-0.22$ & & & \\
\hline \multirow[t]{2}{*}{ Post-RV60Gy ${ }^{b}$} & non-ERB & 1.67 & 4.5 & $0-14.4$ & 1.56 & 4.44 & 0.518 \\
\hline & ERB & 0.11 & 0.23 & $0-0.71$ & & & \\
\hline \multirow[t]{2}{*}{ Post-RV55Gy b } & non-ERB & 2.38 & 5.47 & $0-17.67$ & 2.14 & 5.39 & 0.435 \\
\hline & ERB & 0.24 & 0.46 & $0-1.45$ & & & \\
\hline \multirow[t]{2}{*}{ Post-RV50Gy b } & non-ERB & 3.01 & 6.39 & $0-20.57$ & 2.55 & 6.25 & 0.286 \\
\hline & ERB & 0.451 & 0.70 & $0-2.25$ & & & \\
\hline \multirow[t]{2}{*}{ Post-RV40Gy b } & non-ERB & 4.98 & 8.05 & $0.2-27.09$ & 3.83 & 7.79 & 0.069 \\
\hline & ERB & 1.148 & 1.309 & $0.06-4.03$ & & & \\
\hline \multirow[t]{2}{*}{ Post-RV30Gy b } & non-ERB & 11.59 & 10.90 & $0.88-36.46$ & 8.86 & 9.92 & 0.019 \\
\hline & ERB & 2.7 & 2.26 & $0.33-6.68$ & & & \\
\hline \multirow[t]{2}{*}{ Post-RV20Gy ${ }^{b}$} & non-ERB & 21.92 & 14.84 & $3.83-49.00$ & 15.76 & 12.94 & 0.003 \\
\hline & ERB & 6.165 & 3.711 & $1.59-10.87$ & & & \\
\hline \multirow[t]{2}{*}{ Post-RV10Gy ${ }^{b}$} & non-ERB & 39.54 & 17.17 & $14.87-71.37$ & 25.66 & 14.21 & 0.001 \\
\hline & ERB & 13.88 & 6.695 & $3.97-22.05$ & & & \\
\hline
\end{tabular}

${ }^{a}$ Dose in $\mathrm{Gy} ;{ }^{\mathrm{b}} \mathrm{RVXGy}=$ Percentage of post-rectal volume receiving $X$ dose; ${ }^{\mathrm{c}} \Delta$ difference between the non-ERB plans and the ERB plans (mean value non-ERB plans - mean value ERB plans)

Table 4: NTCP results for the whole rectum comparing between the non-ERB plans and ERB plans: 


\begin{tabular}{|c|c|c|c|c|c|c|c|}
\hline \multirow[t]{2}{*}{ NTCP a } & \multirow{2}{*}{$\begin{array}{l}\text { Study } \\
\text { group }\end{array}$} & \multirow[t]{2}{*}{ mean } & \multirow[t]{2}{*}{ SD } & \multirow[t]{2}{*}{ Range } & \multicolumn{2}{|c|}{$\operatorname{Diff}(\Delta)^{b}$} & \multirow[t]{2}{*}{$P$ value } \\
\hline & & & & & mean & SD & \\
\hline \multirow[t]{2}{*}{ Late rectal bleeding $\geq 2$} & non-ERB & 2.6 & 0.97 & $2-5$ & -0.5 & 1.18 & 0.150 \\
\hline & ERB & 3.1 & 1.1 & $1-5$ & & & \\
\hline \multirow[t]{2}{*}{ Necrosis/stenosis } & non-ERB & 5.5 & 1.78 & $1-7$ & -0.1 & 2.02 & 0.728 \\
\hline & ERB & 5.6 & 2.22 & $1-8$ & & & \\
\hline \multirow[t]{2}{*}{ Late rectal toxicity $\geq 3$} & non-ERB & 13.1 & 1.37 & $11-15$ & -0.2 & 3.82 & 0.593 \\
\hline & ERB & 13.3 & 3.02 & $7-17$ & & & \\
\hline
\end{tabular}

${ }^{a}$ NTCP results in \%; ${ }^{b} \Delta$ difference between the non-ERB plans and the ERB plans (mean value non-ERB plans - mean value ERB plans)

\section{Figures}

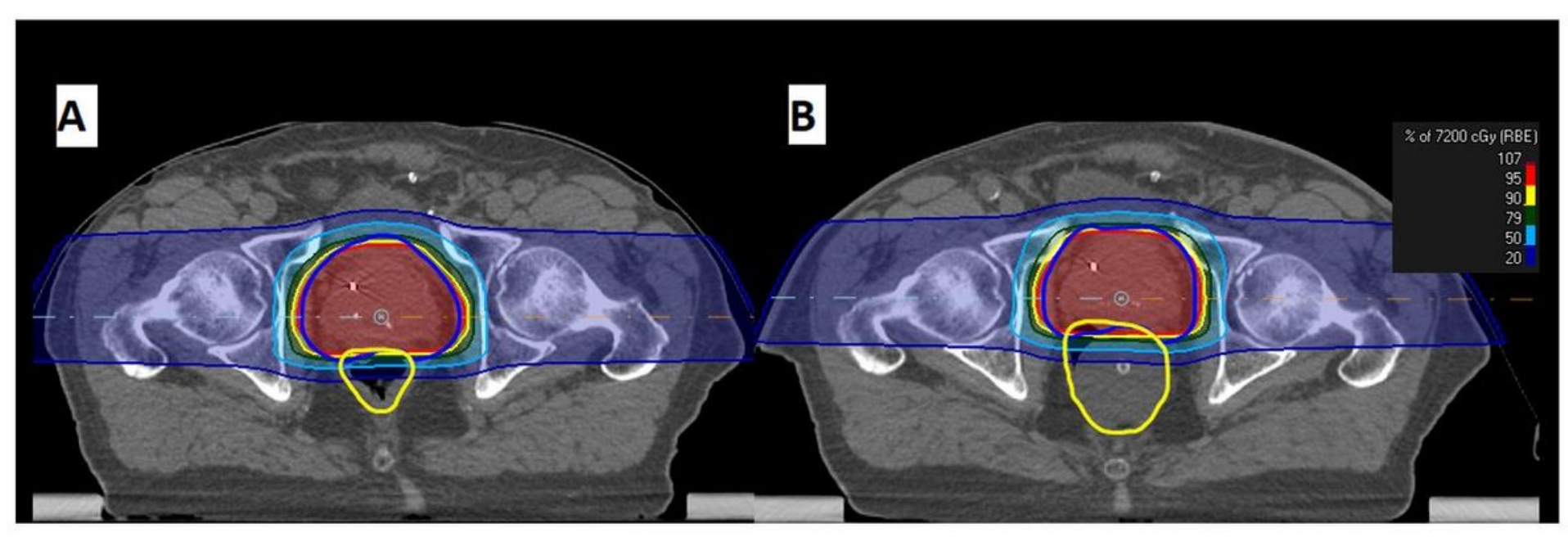

Figure 1

Example of IMPT dose distribution for cT2NOMO Prostate cancer patient. (A) non-ERB plan. (B) ERB plan. 


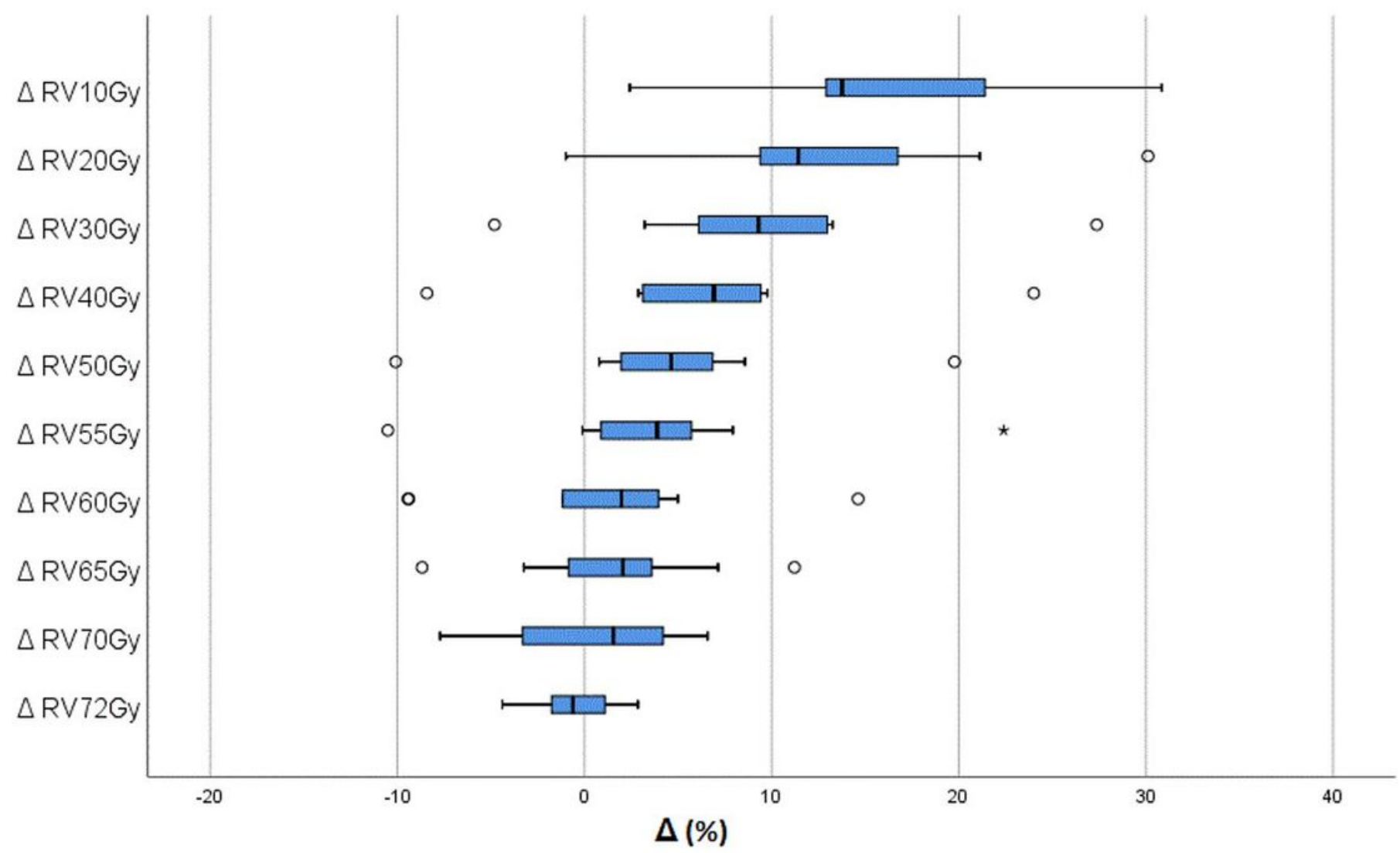

Figure 2

Box plot illustrates the difference $(\Delta)$ in percentage of rectal volume received $x$ dose between the non-ERB plans and ERB plans (mean value non-ERB plans- mean value ERB plans) 


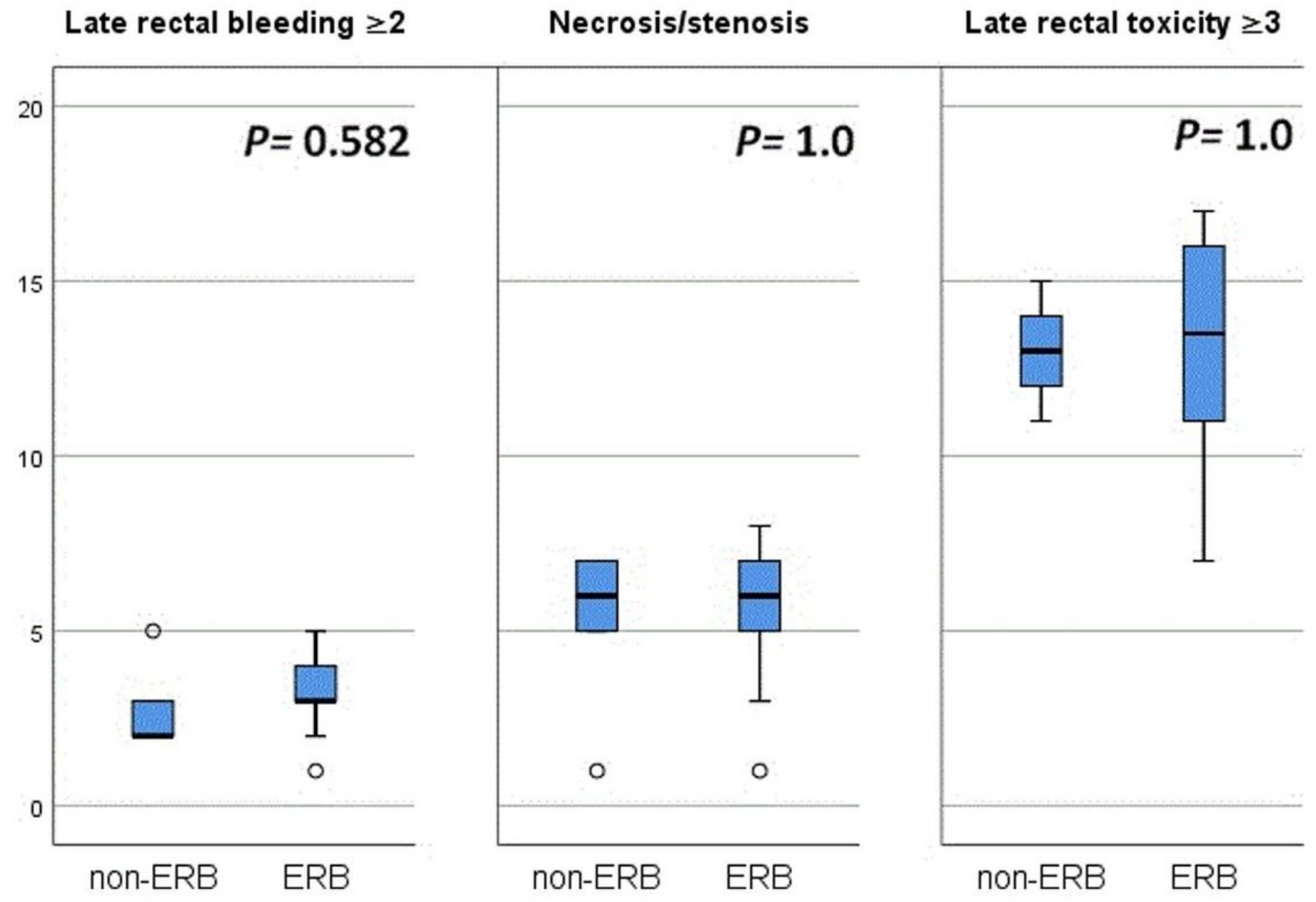

Figure 3

Box plot comparing median and full range of variation of the rectal NTCP rates for late rectal bleeding $\geq$ 2 , necrosis/stenosis, and late toxicity $\geq 3$ for non-ERB plans vs. ERB plans. 